\title{
Super Efficiency and Misallocation: Evidence from Vietnamese Electric-Computer Industry
}

\author{
Nguyen Khac Minh1', Pham Van Khanh'1, Nguyen Thi Phuong² \\ ${ }^{1}$ Thang Long Institute of Mathematics and Applied Science, Hanoi, Vietnam \\ ${ }^{2}$ Faculty of Economics and Management, Thang Long University, Hanoi, Vietnam \\ Email: khanhvietdm@gmail.com
}

How to cite this paper: Minh, N.K., Khanh, P.V. and Phuong, N.T. (2018) Super Efficiency and Misallocation: Evidence from Vietnamese Electric-Computer Industry. American Journal of Operations Research, 8, 63-81.

https://doi.org/10.4236/ajor.2018.82006

Received: January 4, 2018

Accepted: March 6, 2018

Published: March 9, 2018

Copyright () 2018 by authors and Scientific Research Publishing Inc. This work is licensed under the Creative Commons Attribution International License (CC BY 4.0).

http://creativecommons.org/licenses/by/4.0/

\begin{abstract}
Misallocation means that the source is not distributed efficiently. This leads to an important question of how the relationship between misallocation and efficiency is (see [1]). The purpose of this study is to address the empirical relationship between misallocation and efficiency in the electric and computer industry in Vietnam during the $2005-2015$ periods. To do this, we built a model that allowed us to evaluate the impact of misallocation and other factors on efficiency. The slack-based measured efficiency (SBM) model (Tone [2]), and the super-efficient model (Tone [3]) are used to estimate the firms' efficiency. The approach of Hsieh and Klenow [4] is used to measure misallocation in the study area. Estimated results of the model about the relationship between misallocation and efficiency show that the variable representing the misallocation has a negative sign and statistical significance in all models. In other words, the misallocation negatively affects efficiency. The bigger the misallocation, the lower the efficiency.
\end{abstract}

\section{Keywords}

Misallocation, Super-Efficient, Slack-Based Measured Efficiency

\section{Introduction}

According to Solow [5], capital accumulation and technological advances are the bases for explaining why a country is so rich and other countries are too poor. But a new approach has emerged in explaining this question. In this approach, the dominant source of differences in output per capita is differences in TFP, not physical capital or human capital per worker.

Using a model with heterogeneous firms at different distortion levels, Restucia and Rogerson [6] showed that resource misallocation between firms can signifi- 
cantly reduce total factor productivity (TFP). Greenwood et al. [7] showed that expensive tracking technologies of financial intermediaries can significantly reduce TFP as firms have high productivity underfunded whereas low productivity firms are overpriced compared to in the absence of friction. From data on manufacturing plants, Hsieh and Klenow [4] estimated that when misallocation of capital and labor across plants is hypothetically reduced to the level observed in the USA, China's and India's manufacturing TFP increases by 30 - 50 percent and 40 - 60 percent, respectively. Using data from the 2007 Thailand Industrial Census, Siwapong Dheera-Aumpon [8] estimated the misallocation of resources between production plants and its effects on total factor productivity (TFP). He found that there is more resource misallocation between plants in Thailand than in China, India and the United States, as well as in some other countries. When misallocation of resources in Thailand is assumed to be reduced to the level observed in the United States, the TFP of the manufacturing sector increases by about $70 \%$. It has also been found that government-owned plants or located plants in the northern region of Thailand have lower productivity, but face lower input and output distortions than other plants. In addition, medium sized plants face higher distortion than smaller and larger plants.

Using the Italian longitudinal micro-level data sets of manufacturing firms, Sara Calligaris [9] estimated the within-industry misallocation of inputs in Italy in the period 1993-2011, she found that in the hypothesis without the misallocation, TFP in the manufacturing sector would increase by $58 \%$ in 1993 , up $67 \%$ in 2006 and $80 \%$ in 2011. This leads two conclusions. Firstly, misallocation plays an important role in determining the inefficiency of the manufacturing sector. Secondly, the misallocation has increased over time. Given the magnitude of the results achieved and the policy implications associated with it, the author considers the cause of misallocation. The writer argued that misallocation could be attributed to the specific characteristics of firms such as technological level, years of experience, or position because of the misallocation that will be higher for firms located in the south and at low technology intensity, as well as for small or young firms.

Flora Bellone and Jeremy Mallen-Pisano [10] apply the methodology of Hsieh and Klenow to French micro data for manufacturing industries to quantify the intra industry-misallocation in France. Unlike what was found in developing countries like China, India and some Latin American countries, they did not find any significant "efficiency gap" between France and the United States in the manufacturing sector. In particular, the estimated absolute TFP of France due to misallocation is approximately 30 percent, very close to that found in the United States and much lower than the corresponding results found in developing countries (usually 50 to 100 percent). Their results indicate that the methodology of Hsieh and Klenow can detect significant efficiency gaps between developing and developed countries, but it does not do a good job of discriminating between developed countries. However, they argue that continental European economies have higher input and output distortions than the US economy. 
Daniel A. Dias, Carlos Robalo Marques and Christine Richmond [11] extend Hsieh and Klenow's [4] methodology, including intermediate inputs and considering all sectors of the economy (agriculture, production and service) and using Portuguese micro level data sets. They pointed out that the misallocation within the industry has almost doubled between 1996 and 2011. The equivalent of total factor turnover among firms in the industry may have increased by $48 \%$ and increased by $79 \%$ compared to reality in 1996 and 2011 . According to them, the decline in the efficiency of allocations may have decreased by 1.3 percentage points compared to the annual GDP growth rate during 1996-2011. The economic downturn, although a common phenomenon, is significantly higher in the service sector, with five industries accounting for $72 \%$ of the total.

The model developed by Hsieh and Klenow [4] has been applied to data from other countries (Camacho et al. [12]; Ryzhenkov [13]), and the potential benefit of TFP in reducing misallocation has been found to vary over a wide range. TFP gains tended to be large for developing countries, but small for developed countries. In the context of developing countries, the potential for misallocation of resources in Vietnam (see [14]) is high; TFP can be significantly improved by reducing the misallocation. But the change in TFP, as we know it, can break down into changes in technical efficiency and technological progress so the big question is whether the misallocation is associated with inefficiency or not. In developing countries, the government often offers preferential policies to SOEs such as lending or providing other conditions favorable to them. Such government policies lead to misallocation of resources which results in inefficiency. So we expect that the misallocation lead to greater inefficient. This study does not consider this relationship to all industries, but rather focuses on the electric-computer industry, because these industries play an important role in the 4.0 industrial revolution that is taking place every day in the world.

Related to the change of efficiency and technology there are some researches of Minh et al. [15], they used chance-constrained data envelopment approach to decompose provincial productivity growth in Vietnamese agriculture from 1995 to 2007 into technological progress and efficiency change and [16] used stochastic frontier production approach to decompose the sources of total productivity (TFP) growth into technical progress and changes in technical efficiency.

N. Minh, P. Khanh and P. Tuan in [17] based on slacks-based measure of efficiency (SBM) and used super-efficient analysis to rank decision makers.

Another result of the research team is the study of the effectiveness of foreign investment in Vietnam studied in [18]. This research examined impacts of exchange rate volatility and FDI on efficiency of the Vietnamese agricultural sector for the period 1998-2011.

The structure of this study is divided into four sections. In Section 2, the model identifies the impact of misallocation and other factors on the efficiency of the enterprise as well as the models for constructing the dependent variables and the independent variables of the model provided. The data and results are presented 
in Section 3. Finally, the conclusions are discussed together with their implication for improving firm's efficiency that follows.

\section{Methodology: Impacts of Misallocation and Other Factors on Firms' Efficiency Performance}

To construct a model that reflects the relationship between efficiency and misallocation, we need to construct two sets of variables: the dependent variable is the efficiency that estimated from the slack-based measured of efficiency (SBM) and a super-efficient model. Independent variables are misallocation estimated from Hsieh and Klenow's model and other variables that affect efficiency. The main objective of this model is to test the hypothesis that misallocations reduce firms' efficiency and super efficiency. The model can be specified as follows:

$$
\begin{aligned}
\text {TE}_{i j t}= & \alpha_{0}+\alpha_{1} \text { Mis }_{j t}+\alpha_{2} \text { Hor }_{j t}+\alpha_{3} \text { For }_{j t}+\alpha_{4} \text { Back }_{j t}+\alpha_{5} \text { Sback }_{j t}+\alpha_{6} \text { Hc }_{i j t} \\
& +\alpha_{7}(K / L)_{i j t}+\alpha_{8} \text { Age }_{i j t}+\alpha_{9} \text { Scale }_{i j t}+\alpha_{10} \text { Herf }_{j t}+\alpha_{11} \text { FD }_{i j t}+\varepsilon_{i j t}
\end{aligned}
$$

where $T E_{i j t}$ is the efficiency estimated from the slack-based measure of efficiency (SBM) model or the super-efficiency models of firm $i$ in the $f^{\text {th }}$ industry at the time period $t$.

Independent variables are mainly variables that measure misallocation $\left(\mathrm{Mis}_{j t}\right)$.

However, we also add some other independent variables, such as variables denoting FDI transmission channels. Specifically: Horizontal spillover, denoted by Horjt, Forward spillover $\left(\right.$ For $\left._{j t}\right)$, backward spillover $\left(\right.$ Back $\left._{j t}\right)$, and supply-backward spillover $\left(S\right.$ Sback $\left._{j t}\right)$. In addition, the characteristics of firms and industries that can affect firms' performance include human capital (Hcijt), capital intensity $(K / L)_{i j t}$ firm's size $\left(S_{\text {cale }}\right)$, firm's age $\left(A g e_{i j t}\right)$, and industry concentration index $\left(\right.$ herf $\left._{j t}\right)$, technology gap $\left(T G_{i j t}\right)$, and financial development $\left(F G_{i j t}\right)$ in the modele defined below.

Model defined by Equation (1) is a model of the factors affecting efficiency that we will divide into four models for estimation, depending on the difference in the dependent variable and the estimation method. Considering the differences in the dependent variable, we have two pairs of models: models $1 \mathrm{a}$ and $1 \mathrm{c}$ are models with dependent variables which estimated from the SBM model, while models $1 \mathrm{~b}$ and $1 \mathrm{~d}$ are models in which the dependent variables are estimated from the super-efficiency model.

Considering the differences in estimation methods, models $1 \mathrm{a}$ and $1 \mathrm{~b}$ are estimated by the least squares method. Models $1 \mathrm{c}$ and $1 \mathrm{~d}$ are models with dependent variables are censored. The linear Tobit regression in models $1 \mathrm{c}$ and $1 \mathrm{~d}$ is used to identify possible factors associated with inefficiency. Tobit analysis is used because the dependent variables, technical efficiency from SBM model and super efficiency model, are censored variables having upper limit of 1.00 and 5.00 , respectively. Each of these indices is regress on the same explanatory variables. The coefficient of $\alpha_{1}$ provides an idea of how much misallocation affect efficiency. 


\subsection{Models for Estimating Dependent Variables (Efficiency)}

As indicated above, we have to estimate the two dependent variables as the efficiency of the enterprises from the SBM model and the efficiency from the super efficiency model. The building model used here is to evaluate the efficiency performance of firms. In conventional analyzes, such assessments take many forms. For example, the cost per unit, the profit per unit and the satisfaction per unit, etc are measured as a ratio as follows: output/input. This is a commonly used measure. By this measure, the more output and less input is efficient. Below, we will present the efficient models used for this study.

Assume that $x$ represents a vector of $\mathrm{m}$ inputs, $x=\left(x_{1}, x_{2}, \cdots, x_{m}\right) \in R_{m}^{+}, y$ represents the output vector of s outputs $y=\left(y_{1}, y_{2}, \cdots, y_{s}\right) \in R_{s}^{+}$; and there are $\mathrm{n}$ firms. The matrix of observed inputs, $X$, of dimension $(m, n)\left(X=\left(x_{i j}\right) \in R_{m . n}\right)$ and the matrix of observed outputs, $Y$, of dimension $(s, n)\left(Y=\left(y_{i j}\right) \in R_{s . n}\right)$ form a transformation set can be as follows:

$$
T=\left\{(x, y): y \leq Y \lambda, X \lambda \leq x, \lambda \in R_{n}^{+}\right\}
$$

where $R_{n}^{+}=\left\{\lambda=\left(\lambda_{1}, \lambda_{2}, \cdots, \lambda_{n}\right): \lambda \geq 0\right\}$ and $\lambda$ is the vector of intensity variables of activity $\left(x_{i p}, y_{i}\right)$.

The overall technical efficiency can be presented as follows:

$$
\theta^{*}\left(x_{i}, y_{i}\right)=\max \left\{\theta:\left(x_{i}, \theta_{i} y_{i}\right) \in T\right\}
$$

where $\theta$ is the level of inefficiency. The term $\theta_{i} y_{i}$ is actual production of the firm. The firm is technically efficient if $\theta=1$.

There are many models for measuring firms' efficiency such as the CCR model (Charnes-Cooper-Rhodes [19]), the BCC model (Banker-Charnes-Cooper [20]), SBM model (Tone [2], Minh [21]).

In the literature, it has also been shown that the relationship of estimated efficiency from these models such as Jaforullah and Whiteman [22] use the CCR and BCC models to estimate scale efficiency in the New Zealand dairy industry; Yao et al. [16] estimate the technical efficiency of the Chinese insurance industry after accession to the WTO by adopting a DEA approach.

\subsubsection{Slack Based Measure of Efficiency Model for Estimating the Efficiency}

The input-oriented slack based measure of efficiency model can be defined as follow:

$$
\begin{array}{cl}
\left(\text { SBM-I) } \rho_{I}^{*}=\min _{\lambda, s^{-}} 1-\frac{1}{m} \sum_{i=1}^{m} \frac{s_{i}^{-}}{x_{i 0}}\right. \\
\text { subject to } & x_{0}=X \lambda+s^{-} \\
& y_{0} \leq Y \lambda-s^{+} \\
& \lambda \geq 0, s^{+} \geq 0 .
\end{array}
$$

where $\bar{s}\left(\in R^{m}\right)$ is the input excesses and $s^{+}\left(\in R^{s}\right)$ is the output shortfalls. In this model, we can assume that $X \geq 0$. If $x_{i 0}=0$, then we delete the term $\frac{s_{i}^{-}}{x_{i 0}}$ 
in the objective function.

The output-oriented slack based measure of efficiency model can be defined as follow:

$$
\begin{array}{cl}
(\mathrm{SBM}-\mathrm{O}) & \rho_{0}^{*}=\min _{\lambda, s^{+}} \frac{1}{1+\frac{1}{s} \sum_{i=1}^{s} \frac{s_{r}^{+}}{y_{r 0}}} \\
\text { subject to } & x_{0} \geq X \lambda \\
& y_{0}=Y \lambda-s^{+} \\
& \lambda \geq 0, s^{+} \geq 0 .
\end{array}
$$

\subsubsection{Super Efficiency Model for Estimating the Efficiency}

A non radical input-oriented super-efficiency model can be presented as follows:

$$
\begin{gathered}
\text { (SuperSBM-I-C) } \delta_{I}^{*}=1+\frac{1}{m} \sum_{i=1}^{m} \phi_{i} \\
\phi_{i} x_{i 0}+x_{i 0}-\sum_{j=1, \neq 0}^{n} x_{i j} \lambda_{j} \geq 0 \quad(i=1,2, \cdots, m) \\
\sum_{j=1, \neq 0}^{n} y_{r j} \lambda_{j}-y_{r o} \geq 0 \quad(r=1,2, . \cdots, s) \\
\phi_{i} \geq 0(i=1,2, \cdots, m), \lambda_{j} \geq 0(j=1,2, \cdots, n) .
\end{gathered}
$$

In a similar way we can set up the output-oriented super efficiency model as follows:

$$
\begin{gathered}
\text { (SuperSBM-O-C }) \delta_{O}^{*}=\min _{\psi, \lambda} \frac{1}{1-\frac{1}{s} \sum_{r=1}^{s} \psi_{r}} \\
x_{i 0}-\sum_{j=1, \neq 0}^{n} x_{i j} \lambda_{j} \geq 0(i=1,2, \cdots, m) \\
\sum_{j=1, \neq 0}^{n} y_{r j} \lambda_{j}-y_{r o} \psi_{r}-y_{r 0} \geq 0 \quad(r=1,2, \cdots, s) \\
\psi_{r} \geq 0(r=1,2, \cdots, s), \lambda_{j} \geq 0(j=1,2, \cdots, n) .
\end{gathered}
$$

In the case of VRS, we put the convexity constraints to the models:

$$
\sum_{j=1}^{n} \lambda_{j}=1, \lambda_{j} \geq 0 \forall j
$$

\subsection{Estimating Independent Variables}

\subsubsection{Measurement of Misallocation}

In this paper we chose to use the dynamic productivity decomposition framework proposed by Hsieh and Klenow [4] rather than Bartelsman, Haltiwanger and Scarpetta [23]'s productivity decomposition framework to assess misallocation in the Vietnamese manufacturing sector. This choice was mainly dictated by the limited availability of firm level data. The study also used the output elastici- 
ty of capital and labor in each industry as benchmark values for a when a reference with assuming the absence of distortions in US economy.

The Hsieh \& Klenow [4]'s method decomposes misallocation of resources to those arising from output distortion $\tau_{Y_{S_{i}}}$ and those from capital distortion $\tau_{K_{s i}}$. Output distortion $\tau_{Y_{s i}}$ increases the marginal product of capital and labor by the same proportion while capital distortion $\tau_{K_{s i}}$ raises the marginal product of capital relative to labor. The dispersion of TFP presents misallocation and it is defined as the deviation of TFPR and TFPQ, $\log \left(T F P R_{s i} / \overline{T F P R_{s}}\right)$ and $\log \left(T F P Q_{s i} \cdot M_{s}^{1 /(\sigma-1)} / \overline{T F P Q_{s}}\right)$, where TFPQ denotes total factor productivity using real output and TFPR total factor productivity using total revenue of the firm.

The method assumes that an economy consists of hetergeneous firms operating under perfectly competitive final output market. A single final good, $Y$, is produced by a representative firm using the output $Y_{s}$ of $S$ manufacturing industries $(s=1, \cdots, S)$, with the following Cobb-Douglas production technology:

$$
Y=\prod_{s=1}^{S} Y_{s}^{\theta_{s}}
$$

where $\sum^{S} \theta_{s}=1$ and $\theta_{s}$ is the value-added share of industry $s$. With a constant elasticity of substitution (CES) technology, each industry produces output $Y_{s}$ which combines $M_{s}$ differentiated goods produced by individual firm i. Output in industry $s$ is then indicated by the Equation (9):

$$
Y_{s}=\left(\sum_{i=1}^{M_{s}} Y_{s i}^{\frac{\sigma-1}{\sigma}}\right)^{\frac{\sigma-1}{\sigma}} .
$$

The output of firm $i$ in industry $s\left(Y_{s i}\right)$ is presented by a standard Cobb-Douglas function with constant returns to scale:

$$
\begin{gathered}
Y_{s i}=A_{s i} K_{s i}^{\alpha_{s}} L_{s i}^{1-\alpha_{s}} \\
T F P Q_{s i}=A_{s i}=\frac{Y_{s i}}{K_{s i}^{\alpha_{s}} L_{s i}^{1-\alpha_{s}}} \\
T F P R_{s i}=P_{s i} A_{s i}=\frac{P_{s i} Y_{s i}}{K_{s i}^{\alpha_{s}} L_{s i}^{1-\alpha_{s}}} .
\end{gathered}
$$

To deal with the profit maximization in a monopolistic competition market and the equilibrium allocation of resources across industries, a fixed markup over its marginal cost will be added to the firm's output price:

$$
\begin{gathered}
P_{s i}=\frac{\sigma}{\sigma-1}\left(\frac{R}{\alpha_{s}}\right)^{\alpha_{s}}\left(\frac{w}{1-\alpha_{s}}\right)^{1-\alpha_{s}} A_{s i}^{-1} \frac{\left(1+\tau_{K_{s i}}\right)^{\alpha_{s}}}{1-\tau_{Y_{s i}}} \\
1-\tau_{Y_{s i}}=\frac{\sigma}{\sigma-1} \frac{w L_{s i}}{\left(1-\alpha_{s}\right) P_{s i} Y_{s i}} \\
1+\tau_{K_{s i}}=\frac{\alpha_{s}}{1-\alpha_{s}} \frac{w L_{s i}}{R K_{s i}}
\end{gathered}
$$




$$
\operatorname{TFPR}_{s i}=\frac{\sigma}{\sigma-1}\left(\frac{R}{\alpha_{s}}\right)^{\alpha_{s}}\left(\frac{w}{1-\alpha_{s}}\right)^{1-\alpha_{s}} \frac{\left(1+\tau_{K_{s i}}\right)^{\alpha_{s}}}{1-\tau_{Y_{s i}}}
$$

where $\sigma /(\sigma-1)$ is markup of prices over its marginal costs. $K_{s i}, L_{s i}$ are capital and labor of firm $\mathrm{i}$ in industry $s$, respectively and $\alpha_{s}$ is the capital factor share, which is assumed to be the same across firms within industry s but different across industries; $\sigma$ implies the elasticity of substitution between goods; $P_{s i} Y_{s i} \mathrm{~W}$ and $R$ represent the value added, common wages and rental costs, respectively.

Industry TFP can now be calculated as:

$$
T F P_{s}=\left[\sum_{i}^{M_{s}}\left(\operatorname{TFPQ}_{s i} \frac{\overline{T_{F P R_{s}}}}{\operatorname{TFPR}_{s i}}\right)^{\sigma-1}\right]^{\frac{1}{\sigma-1}}
$$

where $\overline{\operatorname{TFPR}_{s}}$ is average industry TFPR; Ms is the number of firms in industry s.

$$
\overline{T F P R_{s}}=\frac{\sigma}{\sigma-1}\left[\frac{R}{\alpha_{s} \sum_{i=1}^{M_{s}} \frac{1-\tau_{Y_{s i}}}{1+\tau_{K_{s i}}} \frac{P_{s i} Y_{s i}}{P_{s}}}\right]^{\alpha_{s}}\left[\frac{w}{\left(1-\alpha_{s}\right) \sum_{i=1}^{M_{s}}\left(1-\tau_{Y_{s i}}\right) \frac{P_{s i} Y_{s i}}{P_{s} Y_{s}}}\right]^{1-\alpha_{s}} .
$$

Because the physical output, $Y_{s i}$, is not observed in the data then the physical productivity $T F P Q_{s i}$ is expressed in terms of revenue $P_{s i} Y_{s i}$

$$
T F P Q_{s i}=A_{s i}=k_{s} \frac{\left(P_{s i} Y_{s i}\right)^{\frac{\sigma}{\sigma-1}}}{K_{s i}^{\alpha_{s}} L_{s i}^{1-\alpha_{s}}}
$$

where

$$
k_{s}=w^{1-\alpha_{s}} \frac{\left(P_{s} Y_{s}\right)^{-\frac{1}{\sigma-1}}}{P_{s}}
$$

$k_{s}$ is a scaling constant that does not affect within-industry reallocation gains so normalized to 1 .

In the absence of distortions, the industry TFPQ is given by the CES aggregate of each individual firm's TFPQ:

$$
\overline{T F P Q_{s}}=\overline{A_{s}}=\left(\sum_{i=1}^{M_{s}} A_{s i}^{\sigma-1}\right)^{\frac{1}{\sigma-1}}
$$

\section{- Misallocation variables of the model}

\section{Misallocation}

The dispersion of TFP presents misallocation and it is defined as the deviation of TFPR and TFPQ from its mean, $\log \left(T F P R_{s i} / \overline{T F P R_{s}}\right)$ and $\log \left(T F P Q_{s i} \cdot M_{s}^{1 /(\sigma-1)} / \overline{T F P Q_{s}}\right)$, where TFPQ denotes total factor productivity using real output and TFPR total factor productivity using total revenue of the firm.

\subsubsection{Measurement of FDI Spillovers}

One of the policies has a strong impact on the allocation of resources among 
firms is the policy of attracting FDI. We will study the impact of FDI on entry and exit behavior and the market share of firms through the spillover channels of FDI as horizontal, forward and backward channels. Based on the studies on FDI (see Aitken \& Harrison [24], Javorcik [25]), we will define these channels as follows. The horizontal spillover variable (Hor) captures the level of foreign presence in sector $j$ at time $t$ and is measured as foreign equity participation averaged over all firms in the sector, weighted by each firms share in sector output:

$$
\operatorname{Hor}_{j t}=\frac{\sum_{i \in j} f s_{i j t} X_{i t}}{\sum_{i \in j} X_{i t}} .
$$

We define the forward spillover variable (For) as:

$$
\text { For }_{j t}=\sum_{k \text { if } k \neq j} \delta_{j k t} H r_{k t}
$$

where the IO table reveals the proportion $\delta_{j l t}$ of industry j's inputs purchased from upstream industries $l$. Inputs purchased within the industry $(I=j)$ are again excluded, since this is already captured by variable Horizontal. The backward spillover variable (Back) is a proxy for the foreign presence in the industries that are being supplied by the sector to which the firm in question belongs and thus intended to capture the extent of potential contracts between domestic suppliers and multinational customers. It can be defined as follows:

$$
\text { Back }_{j t}=\sum_{\text {if } k \neq j} \gamma_{j k t} \text { Hor }_{k t}
$$

where $\gamma_{j k t}$ is the proportion of industry $j$ s output supplied to sourcing industry $k$ at time $t$. The $\gamma s$ are calculated from the time-varying IO tables for intermediate consumption. In the calculation of $\gamma$, we explicitly exclude inputs sold within the firm's industry $(k=j)$ because this is captured by Horizontal variable.

The supply-backward spillover goes from foreign companies through its local suppliers to local customers of these suppliers.

\subsubsection{Frm-Level Characteristics}

$K / L_{i t}$ (Capital_Intensity) is capital stock per employee in million VND at time $t$;

$H c_{i j t}$ (Human_Capital) is measured by total wages and training costs per employee in million of VND;

$S c a l e_{i j t}$ is measured by sales of firm $i$ relative to the average firm sales in the same sector;

$A g e_{i j t}$ is the age of firm $i$, industry $j$, year $t$. The age of firm is calculated from the year of incorporation of the firm;

$\mathrm{FD}_{\mathrm{it}}$ : Financial_Development of firm $i$ in industry $j$ at time $t$ is measured by working capital as a proportion of total assets.

\subsubsection{Industry Variables}

Herf $_{i j t}$ (Concentration) is measured by means of the Herfindahl index for firms. The level of concentration in industry $j$ is defined as follows: 


$$
\operatorname{Herf}_{j t}=\sum_{i \in J}\left(\frac{x_{i j t}}{X_{j t}}\right)^{2}
$$

where $X_{i j t}$ is the sales of the firm i in industry $j$ at time $t$ and $X_{j t}$ is the total sales of industry $j$ at time $t$. An increase in the index indicates that higher industry concentration reflects less competition than the likelihood of entry into the industry and small and medium-sized enterprises as well as low-tech enterprises are excluded from the industry. Thus, the reduction of competition will create a channel for the reduction of the share of large enterprises and high technology enterprises as well as FDI enterprises but may increase the market share of small and medium enterprises as well as private businesses. This analysis shows that the markers of the estimated coefficients of the Herf variable in the different models may be different. We expect the coefficient of this variable in FDI models, SOEs and high tech enterprises to have negative signs. It can be argued that more concentration means that the economy is larger than the share of large firms.

\section{Data and Estimated Results}

\subsection{Data Description}

In this study, the added value is used to estimate the efficiency measures of the electric-computer sector at the firm's data level. However, value-added data is not included in the database and must be calculated from other components. Value added is defined as the value of gross output minus intermediate inputs. Unfortunately, production cost data is not included in the data set. However, according to the General Statistics Office (GSO), value added is defined as the sum of two components: 1) labor compensation; and 2) capital rent payment. Thus, in this paper, the value added is calculated based on the income approach by the determinant of labor income and capital. Information on labor compensation, fixed asset depreciation and profitability is in Vietnam enterprise survey.

For inputs, three input factors are used in the production of output. First, capital input is concerned as the most problematic of input measures. In this study, total assets including liquid assets and fixed assets at the end of the year will be applied as a proxy for capital stock of firms. Second, labor input is measured by the number of full-time employees getting paid by firms at the end of the year is likely to be appropriate. Third, intermediate inputs will be computed by subtracting gross output from value added at constant prices.

To calculate misallocation of Vietnamese manufacturing sector, we also use output elasticity of capital and labor in the US with assuming the absence of misallocation in US economy. The US labor share is taken from the National $\mathrm{Bu}$ reau of Economic Research's NBER-CES industry database from 2000 to 2011 classified by the North American Industrial Classification System (NAICS) version 1997. Based on the data, the NAICS code is linked to the four-digit Vietnam Industrial Classification System. The output elasticity of labor of the United States 
is taken as the ratio of total payroll to total value added in an industry. Elasticity output of capital and labor assumed is constant over time but different between industries.

Summary statistics for key variables are presented in appendix (Tables A1-A3). The average value of value added increased significantly overtime from VND 44,191.9 million/enterprise in 2005 to VND 170,559 million/enterprise in 2015. Meanwhile, the average number of employees tended to decrease. However, the trend of using capital and intermediary input of electricity and electronics enterprises increased sharply during the study period. Perhaps this indicates that this is a young industry with a tendency to use capital intensity. The average amount of capital stock tends to increase from 195,317.5 million VND per firm and 394,532.1 million VND per firm. Intermediate input costs tended to increase from 288,167 million per enterprise to VND 497,679 million per enterprise.

\subsection{Estimated Results of Misallocation}

The dispersion of TFPR and TFPQ, which represents resource misallocation of Vietnamese manufacturing sector in the period 2005-2015, is shown in Table 1 . The tables show the standard deviation, difference between the $90^{\text {th }}$ and $10^{\text {th }}$ percentiles, differences between the $75^{\text {th }}$ and $25^{\text {th }}$ percentiles by year.

The standard deviation of TFPR and TFPQ representing dispersion of TFPR and TFPQ in the Table 1 tends to increase in the phase from 2000 to 2008. In the later phase, the dispersion of TFPR is found to be decreased compared to previous phase and has insignificant change. It can be seen that

Table 1. The dispersion of TFPR and TFPQ by year.

\begin{tabular}{ccccccc}
\hline \multirow{2}{*}{ Year } & \multicolumn{3}{c}{ Dispersion of TFPR } & \multicolumn{3}{c}{ Dispersion of TFPQ } \\
\cline { 2 - 6 } & S.D. & $75-25$ & $90-10$ & S.D. & $75-25$ & $90-10$ \\
\hline 2005 & 0.93 & 0.91 & 1.79 & 1.75 & 2.05 & 4.02 \\
2006 & 0.80 & 1.06 & 2.01 & 1.61 & 2.47 & 4.21 \\
2007 & 0.76 & 0.93 & 1.79 & 1.51 & 2.14 & 3.70 \\
2009 & 1.05 & 1.09 & 2.03 & 1.77 & 2.58 & 4.28 \\
2010 & 0.83 & 1.02 & 1.96 & 1.62 & 2.69 & 4.09 \\
2011 & 0.80 & 0.99 & 1.92 & 1.52 & 1.99 & 4.15 \\
2012 & 0.74 & 0.91 & 1.61 & 1.42 & 1.58 & 3.49 \\
2013 & 0.63 & 0.78 & 1.68 & 1.22 & 1.51 & 2.69 \\
2014 & 0.69 & 0.89 & 1.69 & 1.37 & 1.65 & 3.30 \\
2015 & 0.92 & 0.94 & 1.91 & 1.69 & 1.67 & 3.61 \\
\hline $00-2015$ & 0.79 & 0.92 & 1.80 & 1.52 & 1.96 & 3.65 \\
\hline
\end{tabular}

Source: Estimated from GSO data. 
the negative impact of the credit market related to global financial crisis in two years 2008-2009 has affected the Vietnamese economy, so the dispersion of TFPR and TFPQ reaches the highest value. The dispersion of TFPR and TFPQ later has shown signs of significant improvement since the crisis. The Government of Vietnam has made efforts to improve the capital markets and output markets to reduce misallocation especially with high technology industries. If the dispersion is measured by the difference between the $90^{\text {th }}$ percentile and the $10^{\text {th }}$ percentile or the $75^{\text {th }}$ and $25^{\text {th }}$ percentile, the results are similar.

\subsection{Efficiency Scores of the Models}

Technical efficiency scores were estimated using the DEA-Solver computer program (Cooper et al., 2007) with output-oriented (SBMOC) and super-efficient models for the 1591 enterprise model from 2005 to 2015. Appendices 2 and 3 show summary statistics of the technical efficiency model, estimated results from efficient models based on SBMOC and super-slack efficient models. The average technical efficiency of each firm, estimated from SBMOC tends to decrease from 0.51 in 2000 to 0.39 in 2015 . This decline is probably due to the fact that some enterprises operate poorly because the sector's minimum efficiency score has fallen from 0.01 to approximately zero.

Efficiency scores of firms from the super-efficient model tend to be similar to the performance scores estimated from the SBMOC model. But the findings from the super-efficient model are that even those firms which are considered to be the most efficient also show that their performance points tend to decrease. This is evidenced by the fact that the maximum efficiency has fluctuated over the years and increased from 2.34 in 2005 to 3.81 in 2015.

\subsection{Estimated Results of the Models}

Table 2 presents the results of estimated results on the relationship between efficiency, efficiency and misallocation and some other variables, reflecting the characteristics of enterprises, industries and FDI inflows. Efficiency is estimated from the slack-based models and the super-efficient model estimated from super-slack-based models.

Estimated results of the models (1a), (1b), (1c) and (1d) are presented in Columns 2, 3, 4 and 5 in Table 2. In the second and third columns, we show the estimated results of the model (1a) and the model (1b) using least squares method. Whereas the fourth and fifth columns indicate the estimated results of the model (1c) and (1d) are estimated by the maximum likelihood method. Because the model is modeled with panel data, we use Hausman's test to choose between fixed or random models. The tested results show that the random effect models are more appropriate.

Looking at the results given in the table above, we find that some variables denoting FDI spillovers do not appear because these variables have been removed 
Table 2. Estimated results of the four models.

\begin{tabular}{|c|c|c|c|c|}
\hline & (1a) & (1b) & (1c) & (1d) \\
\hline & \multicolumn{2}{|c|}{ OLS } & \multicolumn{2}{|c|}{ TOBIT } \\
\hline Mis & $\begin{array}{c}-0.053^{\star * *} \\
(0.0163)\end{array}$ & $\begin{array}{c}-0.0739^{* * *} \\
(0.0278)\end{array}$ & $\begin{array}{c}-0.0541^{* * *} \\
(0.0171)\end{array}$ & $\begin{array}{c}-0.0682^{\star * *} \\
(0.0229)\end{array}$ \\
\hline $\mathrm{K} / \mathrm{L}$ & $\begin{array}{l}1.61 \mathrm{E}-05^{\star *} \\
(6.74 \mathrm{E}-06)\end{array}$ & $\begin{array}{c}5.78 \mathrm{E}-05^{\star * *} \\
(1.08 \mathrm{E}-05)\end{array}$ & $\begin{array}{c}2.69 \mathrm{E}-05^{\star * *} \\
(8.93 \mathrm{E}-06)\end{array}$ & $\begin{array}{l}0.00005^{* * *} \\
(9.04 \mathrm{E}-06)\end{array}$ \\
\hline $\mathrm{Hc}$ & $\begin{array}{c}2.27 \mathrm{E}-07^{* * *} \\
(5.92 \mathrm{e}-08)\end{array}$ & $\begin{array}{c}2.42 \mathrm{E}-07^{* * *} \\
(9.42 \mathrm{E}-08)\end{array}$ & $\begin{array}{c}3.19 \mathrm{E}-07^{* * *} \\
(7.72 \mathrm{E}-08)\end{array}$ & $\begin{array}{c}2.83 \mathrm{E}-07^{* * *} \\
(7.91 \mathrm{E}-08)\end{array}$ \\
\hline Scale & $\begin{array}{l}-0.007^{\star * *} \\
(0.0027)\end{array}$ & $\begin{array}{c}-0.0085^{\star *} \\
(0.0042)\end{array}$ & $\begin{array}{c}-0.0069^{* * *} \\
(0.0026)\end{array}$ & $\begin{array}{c}-0.0079^{\star *} \\
(0.0036)\end{array}$ \\
\hline Age & $\begin{array}{c}-0.0124^{\star * \star} \\
(0.0025)\end{array}$ & $\begin{array}{c}-0.0170^{\star * *} \\
(0.0040)\end{array}$ & $\begin{array}{c}-0.0116^{* * *} \\
(0.0025)\end{array}$ & $\begin{array}{c}-0.0168^{\star * \star} \\
(0.0034)\end{array}$ \\
\hline Sback & $\begin{array}{c}3.4426 \\
(3.0433)\end{array}$ & $\begin{array}{c}10.1452^{\star *} \\
(5.1576)\end{array}$ & $\begin{array}{c}3.9237 \\
(3.1747)\end{array}$ & $\begin{array}{l}7.4978^{\star *} \\
(4.2524)\end{array}$ \\
\hline Herf & $\begin{array}{c}0.0668 \\
(0.0569)\end{array}$ & $\begin{array}{c}0.0511 \\
(0.0961)\end{array}$ & $\begin{array}{c}0.0628 \\
(0.0594)\end{array}$ & $\begin{array}{c}0.0670 \\
(0.0793)\end{array}$ \\
\hline $\mathrm{FD}$ & $\begin{array}{c}0.0004 \\
(0.0003)\end{array}$ & $\begin{array}{c}0.0006 \\
(0.0005)\end{array}$ & $\begin{array}{c}0.0004 \\
(0.0003)\end{array}$ & $\begin{array}{c}0.0005 \\
(0.0004)\end{array}$ \\
\hline _cons & $\begin{array}{c}0.5713^{\star * *} \\
(0.0372)\end{array}$ & $\begin{array}{l}0.6444^{\star * *} \\
(0.0602)\end{array}$ & $\begin{array}{c}0.5578^{* * *} \\
(0.0379)\end{array}$ & $\begin{array}{c}0.6341^{\star * *} \\
(0.0504)\end{array}$ \\
\hline sigma_u & 0.1701 & 0.3009 & 0.1814 & 0.244564 \\
\hline sigma_e & 0.1817 & 0.2811 & 0.1788 & 0.2367 \\
\hline Rho & 0.4669 & 0.5340 & 0.5073 & 0.5163 \\
\hline
\end{tabular}

Source: estimation from GSO data.

during the estimation and testing process because they do not make significant. In addition, the results obtained from two different methods of estimation (method of least squares (OLS) and method of maximum likelihood (ML for the Tobit model) yield the same results for the sign, while the magnitude of the estimation coefficients are different not much.

The most important result we obtain from these four models is that the coefficients of the misallocation variables in all four models are negative and statistically significant. This proves that our hypothesis about the reverse relationship between misallocation and efficiency is correct. Because in the sense of misallocation, the source is not allocated to the right place where it is used efficiently, so the higher the misallocation, the lower the efficiency.

Other important variables of firm's characteristics in creating efficiency are the firms' capital intensity that reflects the technical level of the enterprise and the quality of labor. Coefficient of this variable is positive and statistically significant. This result is consistent with previous studies. The same applies to the role of human capital. An increase in human capital increases the firm's efficiency. 
The coefficient of scale variable is negative and statistically significant. This indicates that the larger the scale, the lower the efficiency. This does not seem right in developed countries. However, in the context of developing countries, large-scale electronic firms often dominated by government policies such as receiving more incentives in terms of credit, tax, etc. This leads to a reduction in the actual efficiency within the enterprise.

The estimated results show that the age variable is one of the important variables that determine the technical efficiency of the company. The signs of the age variables in the four models are negative and significant. According to Klepper [26], earlier entrants will have higher survival rates. However, in the high-tech industry that we are considering, the technical innovation is taking place every day. Especially in this industry, most of the older firms are state-owned enterprises. State-owned enterprises receive subsidized or low-interest loans or other rents that the government grants to them, but they operate inefficiently. This explains why the age variables in the models are negative and statistically significant in the three models.

The coefficient of Sback is positive and statistically significant in the models $1 \mathrm{~b}, 1 \mathrm{c}$ and $1 \mathrm{~d}$. The result reflects foreign investors want to stimulate demand for local intermediate products due to the strong vertical integration effects in the electrical-computer industry. From 2015 to now, Vietnam is the $12^{\text {th }}$ largest electronic exporter in the world and the third largest in ASEAN. However, 95\% of the export turnover belongs to the foreign-invested sector. The domestic enterprises of the electrical-computer industry in Vietnam are still in the situation of the assembly and outsourcing mainly for foreign brands.

\section{Conclusions}

This study focused on answering the question of whether misallocation has reduced efficiency or not. In order to answer this question, we set the model of factors determining efficiency in which the dependent variable is technical efficiency and the independent variable is mainly the misallocation measure. In order to structure the dependent variable, we used the slack-based measure (SBM) model and super efficiency models. In order to structure the main independent variable "misallocation", we use the model of Hiesh and Klenow (2009). Other independent variables are also constructed by definition. Using the annual survey data of the General Statistics Office (GSO) of the electrical-computer industry, we set out and estimate the model determining the firms' efficiency of this industry. The results show that the relationship between efficiency and misallocation is reversed, which means that the higher the misallocation, the lower the efficiency. The firm level characteristics including capital intensity or human capital reflect that capital intensive firms with more skilled workers are more likely able to increase the firm's efficiency. This result is consistent with previous studies. The coefficients of scale and age variable are negative and statistically significant. The results reflect large-scale and long-survival firms in the electrical-computer industry often dominated by government policies such as receiving low-interest 
loans or other rents that the government grants to them. This may lead to misallocation of resources among these firms and others in the industry then lower their actual efficiency. The coefficient of Sback is positive, which shows that foreign investors want to stimulate demand for local intermediate products due to the strong vertical integration effects. Developing the electrical-computer industry requires a gradual development process. Instead of expecting to launch an electronic product with a Vietnamese brand name, we should consider the share of domestic firms in the production value of Vietnam electrical-computer industry in particular and global electrical-computer industry in general.

In order to encourage new entrants into the industry to improve the efficiency level, the government needs to reduce misallocation of sources such as removing financial barriers, enhancing tax policies, and improving the importance of international trade. The Government must have a clear and strategic orientation of electronic and information technology products. State management agencies should implement a number of measures to promote industry growth such as attracting selective FDI to increase investment capital and improving the level of competition in the industry, then forcing domestic firms to innovate. Enterprises in the industry should have policies to train workers to improve their skills as well as help workers access high technology quickly. Enterprises in the industry also need to restructure and reallocate capital more efficiently focusing on technology research and development to develop products with good competitiveness.

\section{References}

[1] Midrigan, V. and Xu, D.Y. (2014) Finance and Misallocation: Evidence from Plant-Level Data. American Economic Review, 104, 422-458. https://doi.org/10.1257/aer.104.2.422

[2] Tone, K. (2001) A Slack-Based Measured of Efficiency in Data Envelopment Analysis. European Journal of Operational Research, 130, 498-509. https://doi.org/10.1016/S0377-2217(99)00407-5

[3] Tone, K. (2002) A Slack-Based Measure of Super-Efficiency in Data Envelopment Analysis. European Journal of Operational Research, 143, 32-41. https://doi.org/10.1016/S0377-2217(01)00324-1

[4] Hsieh, C. and Klenow, P. (2009) Misallocation and Manufacturing TFP in China and India. The Quarterly Journal of Economics, 124, 1403-1448. https://doi.org/10.1162/qjec.2009.124.4.1403

[5] Solow, R. (1957) Technical Change and the Aggregate Production Function. Review of Economics and Statistics, 39, 312-320. https://doi.org/10.2307/1926047

[6] Restuccia, D. and Rogerson, R. (2008) Policy Distortions and Aggregate Productivity with Hetero-Geneous Plants. Review of Economic Dynamics, 11, 707-720. https://doi.org/10.1016/j.red.2008.05.002

[7] Greenwood, J., Sanchez, J.M. and Wang, C. (2010) Financing Development: The Role of Information Costs. American Economic Review, 100, 1875-1891. https://doi.org/10.1257/aer.100.4.1875

[8] Dheera-Aumpon, S. (2014) Misallocation and Manufacturing TFP in Thailand. The Australian National University and Wiley Publishing Asia Pty. Ltd., Canberra, Richmond. 
[9] Calligaris, S. (2015) Misallocation and Total Factor Productivity in Italy: Evidence from Firm-Level Data. Centre for Economic and International Studies, 13, 1-34. https://doi.org/10.2139/ssrn.2674157

[10] Bellone, F. and Mallen-Pisano, J. (2013) Is Misallocation Higher in France than in the United States? Working Paper No. 2013-38, Groupe de Recherche en Droit, Economie, Gestion (GREDEG CNRS), University of Nice-Sophia Antipolis, Nice.

[11] Dias, D., Marques, C.R. and Richmond, C. (2016) Misallocation and Productivity in the Lead up to the Eurozone Crisis. Banco de Portugal Working Paper, No. w201411.

[12] Camacho, A. and Conover, E. (2010) Misallocation and productivity in Colombia's manufacturing industries. IDB Working Paper Series. Inter-American Development Bank, Washington DC.

[13] Ryzhenkov, M. (2015) Resource Misallocation and Manufacturing Productivity: The Case of Ukraine. Journal of Comparative Economics, 2015, 1-15.

[14] McMillan, J. and Woodruff, C. (1999) Interfirm Relationships and Informal Credit in Vietnam. Quarterly Journal of Economics, 114, 1285-1320. https://doi.org/10.1162/003355399556278

[15] Minh, N. and Khanh, P. (2011) A Chance-Constrained Data Envelopment Analysis Approach to Problem Provincial Productivity Growth in Vietnamese Agriculture from 1995 to 2007. Open Journal of Statistics, 1, 217-235. https://doi.org/10.4236/ojs.2011.13026

[16] Yao, S., Han, Z. and Feng, G. (2007) On Technical Efficiency of China's Insurance Industry after WTO Accession. China Economic Review, 18, 66-86. https://doi.org/10.1016/j.chieco.2006.10.005

[17] Minh, N., Khanh, P. and Tuan, P. (2012) A New Approach for Ranking Efficient Units in Data Envelopment Analysis and Application to a Sample of Vietnamese Agricultural Bank Branches. American Journal of Operations Research, 2, 126-136. https://doi.org/10.4236/ajor.2012.21015

[18] Minh, N., Khanh, P. and Hung, N. (2015) Impacts of Exchange Rate Volatility and FDI on Technical Efficiency-A Case Study of Vietnamese Agricultural Sector. American Journal of Operations Research, 5, 317-325. https://doi.org/10.4236/ajor.2015.54025

[19] Charnes, A., Cooper, W.W. and Rhodes, E. (1978) Measuring the Efficiency of Decision Making Units. European Journal of Operational Research, 2, 429-444. https://doi.org/10.1016/0377-2217(78)90138-8

[20] Banker, R.D., Charnes, A. and Cooper, W.W. (1984) Some Model for Estimating Technical and Scale Inefficiencies in Data Envelopment Analysis. Management Science, 30, 1078-1092. https://doi.org/10.1287/mnsc.30.9.1078

[21] Minh, N., Khanh, P., Minh, N. and Anh, N. (2012) Productivity Growth, Technological Progress, and Efficiency Change in Vietnamese Manufacturing Industries: A Stochastic Frontier Approach. Open Journal of Statistics, 2, 224-235. https://doi.org/10.4236/ojs.2012.22028

[22] Jaforulla, M. and Whiteman, J. (1999) Scale Efficiency in the New Zealand Dairy Industry: A Non-Parametric Approach. The Australian Journal of Agricultural and Resource Economics, 43, 523-541.

[23] Bartelsman, E., Haltiwanger, J. and Scarpetta, S. (2013) Cross-Country Differences in Productivity: The Role of Allocation and Selection. American Economic Review, 103, 305-334. https://doi.org/10.1257/aer.103.1.305

[24] Aitken, B.J. and Harrison, A.E. (1999) Do Domestic Firms Benefit from Direct For- 
eign Investment? Evidence from Venezuela. American Economic Review, 89, 605-618. https://doi.org/10.1257/aer.89.3.605

[25] Javorcik, B. and Spatareanu, M. (2003) To Share or Not to Share: Does Local Participation Matter for Spillovers from Foreign Direct Investment. The World Bank, Policy Research Working Paper Series No. 3118.

[26] Klepper, S. (2001) The Evolution of the U.S. Automobile Industry and Detroit as Its Capital. Carnegie Mellon University, Mimeo. 


\section{Appendix}

Table A1. (a) Summary statistics for value-added and capital during 2000-2015; (b) Summary statistics for labor and intermediate input, 2000-2015.

(a)

\begin{tabular}{cccccccccc}
\hline \multicolumn{1}{c}{ Value-added } & \multicolumn{1}{c}{ Capital } \\
\hline \multicolumn{1}{c}{ Max } & Min & Average & SD & Max & Min & Average & SD & Obs \\
\hline 2005 & 414,793 & 44 & $44,191.9$ & $69,084.9$ & $1,119,884$ & 2077 & $195,317.5$ & $240,783.1$ & 71 \\
2006 & 872,751 & 316 & $60,926.5$ & $121,825.8$ & $2,016,550$ & 1559 & $266,657.1$ & $364,215.6$ & 75 \\
2007 & 885,124 & 275 & $65,683.8$ & $120,024.8$ & $2,089,330$ & 2585 & $314,668.7$ & $407,484.2$ & 77 \\
2008 & $1,404,946$ & 201 & $76,923.1$ & $165,771.6$ & $2,322,973$ & 1604 & $326,108.6$ & $406,224.8$ & 86 \\
2009 & $1,907,701$ & 459 & $96,319.4$ & $233,876.5$ & $5,082,956$ & 1745 & $370,662.3$ & $642,345.6$ & 102 \\
2010 & $3,174,141$ & 538 & 122,244 & $385,026.7$ & $10,300,000$ & 1861 & $448,624.3$ & $1,026,085$ & 124 \\
2011 & $19,200,000$ & 533 & 223,266 & $1,567,135$ & $38,900,000$ & 808 & $636,240.7$ & $3,174,001$ & 151 \\
2012 & $20,700,000$ & 581 & 268,843 & $1,662,193$ & $64,300,000$ & 482 & $879,222.9$ & $5,111,738$ & 159 \\
2013 & $10,700,000$ & 103.6 & 118,207 & 699,170 & $23,400,000$ & 218 & $316,266.6$ & $1,548,192$ & 248 \\
2014 & $12,800,000$ & 29.1 & 139,484 & $831,975.3$ & $31,200,000$ & 658.7 & 370,949 & $2,045,233$ & 248 \\
2015 & $16,800,000$ & 16 & 170,559 & $1,079,141$ & $32,000,000$ & 717 & $394,532.1$ & $2,097,537$ & 250
\end{tabular}

(b)

\begin{tabular}{ccccccccc}
\hline & \multicolumn{3}{c}{ Labor } & & \multicolumn{5}{c}{ Intermediate inputs } \\
\hline & Max & Min & Average & SD & Max & Min & Average & SD \\
\hline 2005 & 7835 & 25 & 819 & 1516 & $1,693,062$ & 2993 & 288,167 & $384,420.1$ \\
2006 & 8650 & 16 & 951 & 1824 & $3,060,986$ & 1942 & 389,256 & $5,781,23.3$ \\
2007 & 8997 & 21 & 989 & 1808 & $2,699,542$ & 4036 & 446,852 & $606,988.6$ \\
2008 & 9012 & 17 & 956 & 1795 & $3,048,336$ & 1662 & 458,261 & $678,872.4$ \\
2009 & 6396 & 17 & 772 & 1331 & $5,195,297$ & 2040 & 441,271 & $778,861.7$ \\
2010 & 14278 & 13 & 876 & 1800 & $28,000,000$ & 1487 & 723,460 & $2,590,568$ \\
2011 & 20413 & 8 & 977 & 2400 & $109,000,000$ & 537 & $1,225,783$ & $8,839,913$ \\
2012 & 18783 & 11 & 1037 & 2479 & $251,000,000$ & 1425 & $2,281,294$ & $19,840,028$ \\
2013 & 8549 & 5 & 565 & 949 & $45,900,000$ & 234.2 & 441,235 & $2,979,403$ \\
2014 & 10236 & 4 & 597 & 1060 & $50,500,000$ & 216.7 & 494,562 & $3,292,889$ \\
2015 & 10006 & 2 & 583 & 1093 & $51,300,000$ & 166 & 497,679 & $3,305,204$ \\
\hline
\end{tabular}

Sources: Calculation from annual enterprise survey.

Table A2. Summary statistic for technical efficiency estimated results from CCR model.

\begin{tabular}{cccccccccccc}
\hline CCR & 2005 & 2006 & 2007 & 2008 & 2009 & 2010 & 2011 & 2012 & 2013 & 2014 & 2015 \\
\hline No. of DMUs & 71 & 75 & 77 & 86 & 102 & 124 & 151 & 159 & 248 & 248 & 250 \\
Average & 0.51 & 0.42 & 0.42 & 0.4 & 0.41 & 0.38 & 0.42 & 0.39 & 0.4 & 0.4 & 0.39 \\
SD & 0.29 & 0.27 & 0.25 & 0.29 & 0.26 & 0.25 & 0.25 & 0.24 & 0.23 & 0.24 & 0.22 \\
Maximum & 1 & 1 & 1 & 1 & 1 & 1 & 1 & 1 & 1 & 1 & 1 \\
Minimum & 0.01 & 0.06 & 0.02 & 0.01 & 0.03 & 0.02 & 0.01 & 0.05 & 0.01 & 0 & 0 \\
\hline
\end{tabular}


Table A3. Summary statistics for super efficiency estimated results from super-slack based model.

\begin{tabular}{cccccccccccc}
\hline Super & 2005 & 2006 & 2007 & 2008 & 2009 & 2010 & 2011 & 2012 & 2013 & 2014 & 2015 \\
\hline No. of DMUs & 71 & 75 & 77 & 86 & 102 & 124 & 151 & 159 & 248 & 248 & 250 \\
Average & 0.56 & 0.47 & 0.48 & 0.45 & 0.43 & 0.4 & 0.49 & 0.43 & 0.41 & 0.41 & 0.36 \\
SD & 0.41 & 0.42 & 0.52 & 0.44 & 0.35 & 0.32 & 0.57 & 0.41 & 0.28 & 0.27 & 0.32 \\
Maximum & 2.34 & 2.51 & 4.34 & 2.37 & 1.95 & 1.86 & 4.83 & 4.08 & 2.14 & 2.3 & 3.81 \\
Minimum & 0.01 & 0.06 & 0.02 & 0.01 & 0.03 & 0.02 & 0.01 & 0.05 & 0.01 & 0 & 0 \\
\hline
\end{tabular}

